Article

\title{
Profiling of Omega-Polyunsaturated Fatty Acids and Their Oxidized Products in Salmon after Different Cooking Methods
}

\author{
Kin Sum Leung ${ }^{1}$, Jean-Marie Galano ${ }^{2}$, Thierry Durand ${ }^{2}$ and Jetty Chung-Yung Lee ${ }^{1, *(1)}$ \\ 1 School of Biological Sciences, The University of Hong Kong, Pokfulam Road, Hong Kong, China; \\ sam612@connect.hku.hk \\ 2 Institut des Biomolécules Max Mousseron (IBMM), UMR 5247, CNRS Université de Montpellier, ENSCM, \\ F-34093 Montpellier, France; jgalano@univ-montp1.fr (J.-M.G.); thierry.durand@umontpellier.fr (T.D.) \\ * Correspondence: jettylee@hku.hk; Tel.: +852-2299-0318
}

Received: 5 June 2018; Accepted: 14 July 2018; Published: 24 July 2018

\begin{abstract}
Consumption of food containing n-3 PUFAs, namely EPA and DHA, are known to benefit health and protect against chronic diseases. Both are richly found in marine-based food such as fatty fish and seafood that are commonly cooked prior to consumption. However, the elevated temperature during cooking potentially degrades the EPA and DHA through oxidation. To understand the changes during different cooking methods, lipid profiles of raw, boiled, pan-fried and baked salmon were determined by LC-MS/MS. Our results showed that pan-frying and baking elevated the concentration of peroxides in salmon, whereas only pan-frying increased the MDA concentration, indicating it to be the most severe procedure to cause oxidation among the cooking methods. Pan-frying augmented oxidized products of n-3 and n-6 PUFAs, while only those of n-3 PUFA were elevated in baked salmon. Notably, pan-frying and baking increased bioactive oxidized n-3 PUFA products, in particular $\mathrm{F}-4 \mathrm{t}$-neuroprostanes derived from DHA. The results of this study provided a new insight into the application of heat and its effect on PUFAs and the release of its oxidized products in salmon.
\end{abstract}

Keywords: salmon; cooking; lipid peroxidation; polyunsaturated fatty acids; neuroprostanes

\section{Introduction}

Long chain n-3 polyunsaturated fatty acids (PUFA), including $\alpha$-linolenic acid (ALA), eicosapentaenoic acid (EPA) and docosahexaenoic acid (DHA), are important to human health, as they have been reported to protect against cardiovascular disease and neurodegeneration and to reduce inflammation [1-6]. Consumption of dietary n-3 PUFAs is necessary, as ALA cannot be synthesized in the human body due to the absence of $\Delta^{12}$ - and $\Delta^{15}$-desaturase enzymes and the low conversion efficiency of ALA to EPA and DHA in the metabolism. Both EPA and DHA are obtained through our diet, mainly from marine-based food such as fish oil, fatty fish and seafood [7]. However, due to hygiene reasons, it is rare to consume fish raw, and instead, it is commonly cooked by steaming, boiling, pan-frying, baking or roasting prior to consumption. The high temperature generated from these cooking methods could degrade EPA and DHA by breaking down the double bonds for oxidation. Some studies found that the levels of EPA and DHA in marine species were reduced after long-term storage and heat treatment [8-11], while others reported that the levels of EPA and DHA in certain fish species remained unchanged after cooking [12-14].

The high temperature generated during cooking increases the formation of free radicals and reactive oxygen species (ROS) and primarily releases products such as peroxides. On further oxidation, secondary products, namely the aldehydes or alcohol-derived compounds of the hydroperoxide 
primary metabolites, are released. For instance, $\mathrm{F}_{2}$-isoprostanes derived from arachidonic (AA) is a well-known biomarker for oxidative stress in diseases [15], but little is known about its role or generation in food. Likewise, an increasing amount of studies has shown that oxidized products formed through peroxidation of EPA and DHA are beneficial to our health. For example, $\mathrm{F}_{3}$-isoprostanes $\left(\mathrm{F}_{3}\right.$-IsoPs) derived from EPA are anti-inflammatory and anti-thrombotic, as they lower the production of pro-inflammatory prostaglandins and thromboxanes derived from arachidonic acid (AA) by competing for the cyclooxygenase enzyme activity [16]. In addition, some neuroprostanes derived from DHA such as $4-(R S)-4-\mathrm{F}_{4}$ - neuroprostane (NeuroP) are cardio-protective by reducing the risk of ischemia injury in the heart. Furthermore, $4-(R S)-4-\mathrm{F}_{4}-\mathrm{NeuroP}$ was found to prevent post-translational modification of the type 2 ryanodine receptor (RyR2) in cardiac cells [17]. Such an effect restored calcium homeostasis in the heart and reduced arrhythmia. $\mathrm{A}_{4}$-NeuroP and $\mathrm{J}_{4}$-NeuroP are proposed to be have anti-inflammatory properties $[17,18]$ that could bind and activate peroxisome proliferator-activated receptors (PPARs) to reduce the expression of cytokines IL- 6 and TNF- $\alpha$ in response to the inflammation of macrophages [19].

Nevertheless, oxidation of DHA also releases other oxidized products such as 4-hydroxy-2-hexenal (4-HHE). It is the major secondary lipid peroxidation products of DHA that is claimed to be neurotoxic in neuronal cells by augmenting ROS activity and down-regulating antioxidant enzyme and glutathione (GSH) levels [20]. However, recently, there have been studies suggesting that low dose 4-HHE is cardioprotective through the activation of Nrf2 in the vascular cells [21,22].

In this study, the effect of cooking methods on the quality of the PUFA of fatty fish (salmon) was investigated by examining the level of lipid peroxidation and the quantification of PUFA and the oxidized product content of the raw and cooked salmons.

\section{Materials and Methods}

\subsection{Fish Samples and Heat Treatment}

Fresh, deskinned salmon filets were purchased from a local food market and stored in refrigerators $\left(<4{ }^{\circ} \mathrm{C}\right)$ for $2 \mathrm{~h}$ before cooking and extraction for analysis. A total of 16 filets, each $100 \mathrm{~g}$, was divided into four groups including raw as the control, boiling, pan-frying and oven-baking. Details of the cooking process are outlined below.

1. Boiling: Salmon filets were boiled individually on a heat plate in $800 \mathrm{~mL}$ of water initially at $99 \pm 1{ }^{\circ} \mathrm{C}$ for $10 \mathrm{~min}$.

2. Pan-frying: Salmon filets were fried on a medium-sized frying pan on a heat plate to a center temperature of $200 \pm 10^{\circ} \mathrm{C}$ for $10 \mathrm{~min}$ and were flipped over half way ( $5 \mathrm{~min}$ ) through cooking.

3. Oven-baking: The oven was pre-heated to $200{ }^{\circ} \mathrm{C}$. Salmon filets were individually placed on an aluminum foil-coated metal tray and baked at $200{ }^{\circ} \mathrm{C}$ for $15 \mathrm{~min}$.

No cooking oil was added in any cooking method to ensure that the lipids of the samples were from the salmon only. Thereafter, the cooked salmons were cooled to room temperature and stored at $-80{ }^{\circ} \mathrm{C}$ until analysis.

\subsection{Extraction of Crude Oil}

Raw and cooked salmon samples (50 g) were chopped finely by hand. The oil content was derived in a Soxhlet extractor with $500 \mathrm{~mL}$ of n-hexane/diethyl ether $(80: 20, v / v)$ for $8 \mathrm{~h}$. The oil collected was cooled to room temperature and dried completely using nitrogen gas. The dried oil was purged with nitrogen and stored at $-80^{\circ} \mathrm{C}$ until further analysis.

\subsection{Measurement of Lipid Peroxidation}

A portion of the oil sample $(1 \mathrm{~g})$ collected was used for the peroxide value (PV) test to determine total lipid peroxides and the primary lipid peroxidation products, and another portion $(1 \mathrm{~g})$ of the oil 
sample extracted was used to estimate malondialdehyde (MDA) content using the thiobarbituric acid reactive substances (TBARS) test.

The peroxide levels, expressed as peroxide value of the oil, were measured by the conversion of potassium iodide to release iodine according to the Toru et al. method [23]. In brief, $1.0 \mathrm{~g}$ of the oil sample was weighed in an Erlenmeyer flask $(125 \mathrm{~mL})$ and dissolved with $30 \mathrm{~mL}$ acetic acid/ chloroform $(3: 2, v / v)$ solution. A volume of $0.5 \mathrm{~mL}$ saturated potassium iodide solution was then added to the dissolved oil, and the mixture was diluted with $30 \mathrm{~mL}$ of distilled water. The sample mixture was first titrated with $0.01 \mathrm{M}$ sodium thiosulfate until it turned pale yellow. Then, $1 \mathrm{~mL}$ of starch indicator was added, and titration was continued until the disappearance of the dark blue color in the solution.

TBARS test was measured based on the reaction between TBA with MDA and other confounding components according to the Papastergiadis et al. method [24]. In brief, $0.5 \mathrm{~g}$ of oil were dissolved in $10 \mathrm{~mL}$ toluene and reacted with $10 \mathrm{~mL}$ TBA reagent. The reaction mixture was swirled and vigorously shaken for $4 \mathrm{~min}$, and the layers were separated by a separatory funnel. The lower phase was collected and heated in a boiling water bath for $10 \mathrm{~min}$. After cooling down under running tap water, the absorbance of the samples was measured by spectrophotometer at $530 \mathrm{~nm}$, and the concentration of MDA was calculated by using the equation generated by the MDA standard curve.

Corn oil (Lion \& Globe, Hong Kong, China) purchased from a local market was stored at room temperature for 4 years to serve as the positive control for the PV and TBARS tests.

\subsection{Extraction of Polyunsaturated Fatty Acids and Oxidized Products}

PUFA and oxidized lipid products were extracted from salmon samples by Folch extraction as reported previously [25]. In brief, $0.05 \mathrm{~g}$ of finely-chopped salmon samples were homogenized in $10 \mathrm{~mL}$ of Folch solution (chloroform/methanol 2:1 $v / v+0.05 \%$ BHT) using a blade homogenizer (T25, ULTRA-TURRAX, IKA, Guangzhou, China). Afterwards, $2 \mathrm{~mL}$ of $0.9 \% \mathrm{NaCl}$ were added to create a phase separation and extraction. After centrifugation at $800 \times g$ for $10 \mathrm{~min}$ at $4{ }^{\circ} \mathrm{C}$, the lower organic phase was transferred to a glass vial, and the solvent was evaporated under a stream of nitrogen gas. The dried extract was re-suspended in $1 \mathrm{M}$ potassium hydroxide in methanol (1:1). The samples were then hydrolyzed overnight, in the dark, at room temperature $\left(25^{\circ} \mathrm{C}\right)$. After hydrolysis, the samples were cooled and neutralized by hydrochloric acid. Finally, formic acid ( $\mathrm{pH} 4.5)$ was added, mixed together with heavy isotope internal standards $4-(R S)-4-\mathrm{F}_{4 \mathrm{t}}-\mathrm{NeuroP}-\mathrm{d}_{4}$ and $10-\mathrm{F}_{4 \mathrm{t}}-\mathrm{NeuroP}-\mathrm{d}_{4}$ synthesized by Institut des Biomolécules Max Mousseron (IBMM, Montpellier, France) and isoprostanes (IsoP) including $5-\mathrm{F}_{2 \mathrm{t}}-\mathrm{IsoP}-\mathrm{d}_{11}, 15-\mathrm{F}_{2 \mathrm{t}}-\mathrm{IsoP}_{-} \mathrm{d}_{4}, \mathrm{PGF}_{2 \alpha}-\mathrm{d}_{4}$, hydroxyeicosatetraenoic acid (HETE), namely $5(S)$-HETE- $\mathrm{d}_{8}, 12(S)$-HETE- $\mathrm{d}_{8}, 15(S)$-HETE- $\mathrm{d}_{8},{ }_{2}$ 20-HETE- $\mathrm{d}_{6}$, AA- $\mathrm{d}_{8}$, EPA- $\mathrm{d}_{5}$ and DHA- $\mathrm{d}_{5}$ (Cayman Chemicals, Ann Arbor, MI, USA). Finally, the samples were cleaned and extracted using anionic exchange solid phase extraction columns (60 mg, Oasis MAX, Waters, Milford, MA, USA), as described in our previous study [26].

\subsection{Quantification of Polyunsaturated Fatty Acids and Its Oxidized Products}

The extracted PUFA and its oxidized products were analyzed according to previous studies with modifications $[27,28]$. A liquid chromatography tandem mass spectrometry (LC-MS/MS) system consisting of a 1290 Infinity LC system (Agilent, Santa Clara, CA, USA) with a C18 column $(2.6 \mu \mathrm{m}$ particle size, $150 \times 2.1 \mathrm{~mm}$, Phenomenex, Torrance, CA, USA) set to $30^{\circ} \mathrm{C}$ was used. The mobile phase consisted of $0.1 \%$ formic acid in water (A) and $0.1 \%$ formic acid in acetonitrile (B). The flow rate was set to $200 \mu \mathrm{L} / \mathrm{min}$, and the injection volume was $10 \mu \mathrm{L}$. The gradient was first maintained at $10 \% \mathrm{~B}$ from 0 to $1 \mathrm{~min}$, then a linear gradient from $10 \% \mathrm{~B}$ to $98 \% \mathrm{~B}$ for $7 \mathrm{~min}$, then $98 \% \mathrm{~B}$ held for 4 min and, finally, a linear gradient from $98 \%$ B to $10 \%$ B for $0.1 \mathrm{~min}$. Thereafter, the column was re-equilibrated to the starting condition. A QTrap 3200 triple quadrupole mass spectrometer (Sciex Applied Biosystems, Framingham, MA, USA) coupled to the LC was operated at negative atmospheric pressure chemical ionization (APCI) mode. The spray voltage was set to $-4000 \mathrm{~V}$, and nitrogen 
gas was used as the curtain gas. The scan mode was multiple reaction monitoring (MRM), and the MS/MS transition (Figure 1) was monitored according to our previous reports [27,28]. Quantitation of each analyte was determined by relating the peak area with its corresponding deuterated internal standard peak including AA, EPA, DHA, 5(S)-, 12(S)-, 15(S)-, 20(S)-HETE, 15- Ft $_{2}$-IsoP, 5- 2t $_{2}$-IsoP, $4-(R S)-4-\mathrm{F}_{4 \mathrm{t}}-\mathrm{NeuroP}$ and $10-\mathrm{F}_{4 \mathrm{t}}-\mathrm{NeuroP}$. For the analytes without the corresponding deuterated internal standards, i.e., adrenic acid (AdA), 8(S)-, 9(S)-, 11(S)-HETE, 7-F 2 -dihomo-IsoP, 17-F2t-dihomo-IsoP, 7- $\mathrm{F}_{2 \mathrm{t}}$-dihomo-isofuran, 17- $\mathrm{F}_{2 \mathrm{t}}$-dihomo-isofuran, resolvin $\mathrm{E} 1$, 5- $\mathrm{F}_{3 \mathrm{t}}-\mathrm{IsoP}, 8-\mathrm{F}_{3 \mathrm{t}}-\mathrm{IsoP}, 15-\mathrm{F}_{3 \mathrm{t}}$-IsoP, resolvin D1, 4(RS)-ST- $\Delta^{5}-8$-neurofuran, $14(R S)-14-\mathrm{F}_{3 \mathrm{t}}$-IsoP and $4-\mathrm{F}_{3 \mathrm{t}}$-IsoP, quantitation was done by using deuterated internal standards with the relative response factor.

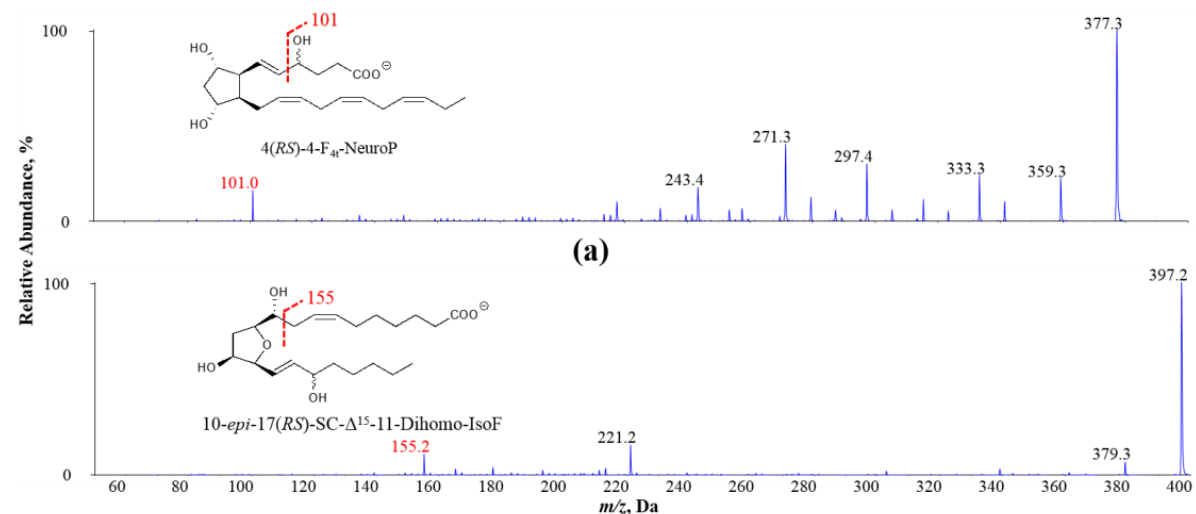

(b)

Figure 1. Exemplary MS/MS spectra of oxidized PUFA products (a) 4(RS)-4- $\mathrm{F}_{4 \mathrm{t}} \mathrm{-NeuroP}$ derived from DHA and (b) 10-epi-17(RS)-SC- $\Delta^{15}$-11-dihomo-IsoF derived from AdA: adrenic acid; NeuroP: neuroprostane; IsoF: isofuran.

\subsection{Extraction of Reactive Aldehydes, 4-Hydroxy-2(E)-Hexenal and 4-Hydroxy-2-Nonenal}

Reactive aldehydes including 4-HHE and 4-HNE were extracted and derivatized from salmon samples according to Douny et al., with modifications [29]. In brief, $1 \mathrm{~g}$ of salmon samples was homogenized with $200 \mu \mathrm{L}$ of BHT solution $(1 \mathrm{mg} / \mathrm{mL}$ in ethanol) and $2200 \mu \mathrm{L}$ of ethanol-water $(50: 50 v / v)$ by using a blade homogenizer (T25, ULTRA-TURRAX, IKA). A volume of $100 \mu \mathrm{L}$ of internal standard mix containing $4-H H E-\mathrm{d}_{3}$ and $4-\mathrm{HNE}-\mathrm{d}_{3}(0.25 \mathrm{ng} / \mu \mathrm{L}$ in ethanol $)$ was added to the homogenates and vortexed for $1 \mathrm{~min}$. Afterwards, the samples were centrifuged at $2100 \times g$ for $10 \mathrm{~min}$. A volume of $2 \mathrm{~mL}$ supernatant was collected, filtered with hydrophilic filter and transferred into a new glass tube. Then, $2 \mathrm{~mL} 0.05 \mathrm{M}$ 2,4-dinitrophenylhydrazine (DNPH)solution in acetonitrile/acetic acid $(9: 1 v / v)$ were added to the extract, and the samples were incubated in a $60{ }^{\circ} \mathrm{C}$ water bath for $2 \mathrm{~h}$ to derivatize the reactive aldehydes and internal standards. Thereafter, $2 \mathrm{~mL}$ of Milli-Q water and $2 \mathrm{~mL}$ of hexane were added to the mixture. To increase the yield, the derivatized extract was collected again with $2 \mathrm{~mL}$ hexane. The hexane extracts were combined and dried under a stream of nitrogen. The dried extract was resuspended with $100 \mu \mathrm{L}$ of $0.1 \%$ acetic acid/acetonitrile $(60: 40 v / v)$, and LC-MS/MS analysis was performed immediately.

\subsection{Quantification of 4-HHE and 4-HNE}

4-HHE and 4-HNE were measured in the samples by LC-MS/MS using ExionLC ${ }^{\text {тм }}$ AC analytical HPLC with a C18 column ( $2.6 \mu \mathrm{m}$ particle size, $150 \times 2.1 \mathrm{~mm}$, Phenomenex, Torrance, CA, USA) maintained at $30^{\circ} \mathrm{C}$. The mobile phase consisted of $0.1 \%$ acetic acid in water $(\mathrm{A})$ and $0.1 \%$ acetic acid in acetonitrile (B). The flow rate was set to $300 \mu \mathrm{L} / \mathrm{min}$, and the injection volume was $20 \mu \mathrm{l}$. The gradient was first increased from $40 \%$ B to $65 \%$ B for $8.5 \mathrm{~min}$, then gradually increased to $100 \%$ B for 4 min and maintained for $7.5 \mathrm{~min}$. Thereafter, the column was re-equilibrated to the starting condition. A Sciex X500R QTOF System mass spectrometer (Sciex Applied Biosystems, Framingham, MA, USA) coupled 
to the LC was operated at negative electrospray ionization, where the source temperature was set to $500{ }^{\circ} \mathrm{C}$. The scan mode was multiple reaction monitoring (MRM), and the MS/MS transition was monitored as $293.09 \rightarrow 167.01$ for 4 -HHE-DNPH, 335.14 $\rightarrow 167.01$ for $4-H N E-D N P H, ~ 296.09 \rightarrow 167.01$ for $4-H H E-d_{3}$ and $338.14 \rightarrow 167.01$ for $4-H N E-d_{3}$. Quantitation of 4-HHE and 4-HNE was determined by relating the peak area to its corresponding deuterated internal standard peak.

\subsection{Statistical Analysis}

Statistical analysis was performed using GraphPad Prism Version 6.0 (GraphPad Prism, La Jolla, CA, USA). All values were expressed as the mean \pm standard deviation (SD). Differences between more than three groups were analyzed by 1-way analysis of variance (ANOVA), and $p<0.05$ was noted as statistically significant.

\section{Results}

\subsection{Different Cooking Methods Did Not Reduce PUFAs' Levels in Salmon}

The content of PUFAs determined in the prepared salmon samples is shown in Figure 2. Surprisingly, different cooking methods did not significantly reduce the concentration of AA, AdA, EPA and DHA of the salmons. Although there was a tendency for a significant change in some PUFA levels by the heat treatments, the large standard deviation of the mean $(\sim 50 \%)$ hampered the statistical relevance. Notably, the large deviation was more prominent when the salmon was fried or baked.

(a)

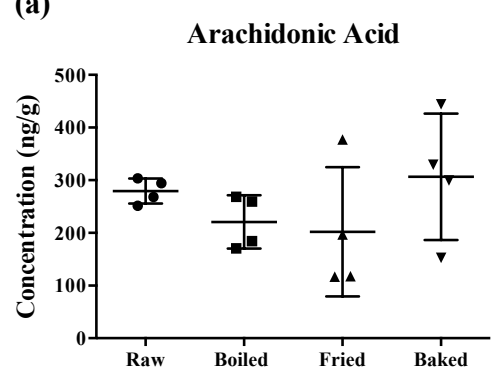

(c)

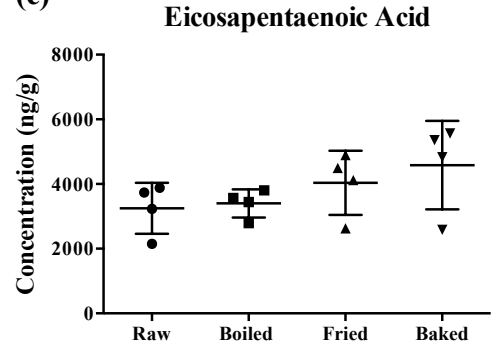

(b)

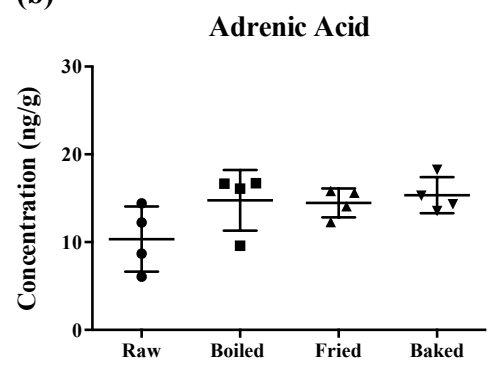

(d)

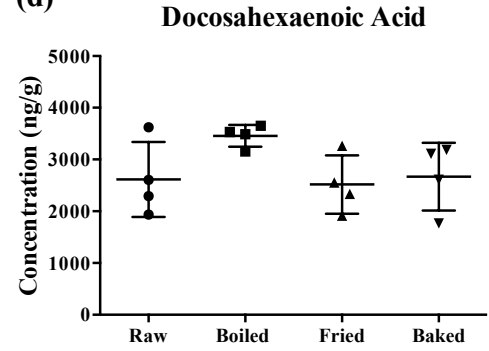

Figure 2. Concentration of polyunsaturated fatty acids measured in salmon samples. Graphs represent (a) arachidonic acid, (b) adrenic acid, (c) eicosapentaenoic acid and (d) docosahexaenoic acid measured in salmon samples. Data are presented as the mean \pm S.D. $(n=4)$. Raw: control salmons without any cooking; boiled: salmons cooked by boiling; fried: salmons cooked by pan-frying; baked: salmons cooked by oven-baking.

\subsection{Elevated Lipid Peroxidation Was Found in Pan-Fried and Oven-Baked Salmons}

Lipid peroxidation was assessed in the cooked salmon and in old corn oil by the PV and TBARS tests (Figure 3). The corn oil (expired for four years) was used as a positive control and had approximately a 60-fold higher level for the PV value and a five-fold higher MDA level compared to raw salmon. Boiling did not increase PV and MDA significantly compared to raw salmon. However, 
a significant increase in PV was found in pan-fried and oven-baked salmon, and increased MDA was found in pan-fried salmon only, compared to other salmon samples. The elevation of peroxides showed that pan-frying and oven-baking indeed increased the extent of primary oxidation in the salmon. In addition, the higher level of MDA observed in pan-fried salmon suggested it to be more detrimental compared to other cooking methods.

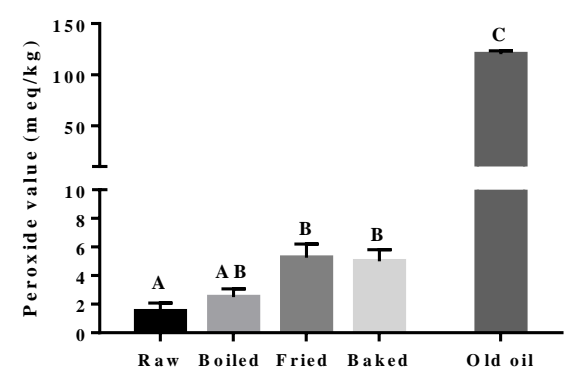

(a)

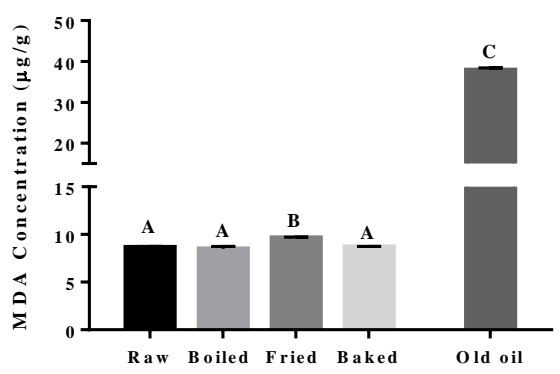

(b)

Figure 3. Level of lipid peroxidation in salmon samples measured by the peroxide value (PV) test and the thiobarbituric acid (TBARS) test. Graphs showing (a) PV and (b) malondialdehyde (MDA) measured in the oil extracted from salmon samples. Data are presented as the mean \pm S.D. $(n=4)$. Raw: control salmons without any cooking; boiled: salmons cooked by boiling; fried: salmons cooked by pan-frying; baked: salmons cooked by oven-baking; old oil: corn oil expired for four years as the positive control. A similar letter denotes no statistical differences between samples, otherwise it is statistically significant at $p<0.05$.

\subsection{Elevated 4-HHE and 4-HNE Were Found in Cooked Salmons}

Reactive aldehydes derived from n-3 PUFA and n-6 PUFA, namely 4-HHE and 4-HNE respectively, were measured in the salmon samples by LC-MS/MS (Figure 4). A significant elevation of 4-HHE and 4-HNE was found in pan-fried samples compared to raw and boiled salmon samples. Similar to what was observed in the PV and TBARS tests, pan-fried salmon contained the highest levels of 4-HHE and 4-HNE, followed by oven-baked, boiled and raw salmons. Among all salmon samples, the level of 4-HHE was higher compared to the level of 4-HNE likely due to higher n-3 PUFA than n-6 PUFA content in the salmons. The elevation of 4-HHE and 4-HNE found in pan-fried salmons indicated that lipid peroxidation of both n-3 PUFA and n-6 PUFA was escalated by pan-frying.

4-H HE

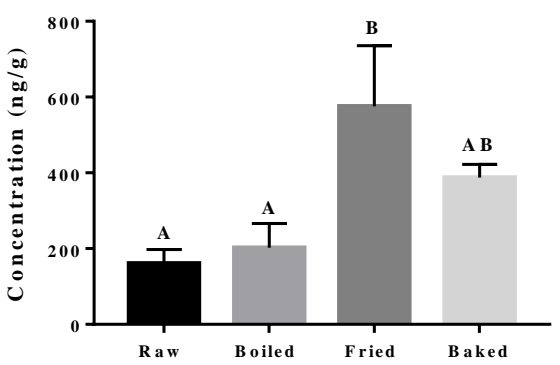

(a)

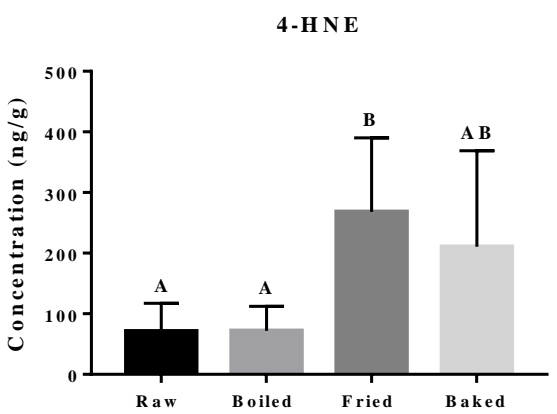

(b)

Figure 4. Levels of 4-hydroxy-2(E)-hexenal (4-HHE) and 4-hydroxy-2-nonenal (4-HNE) in salmon samples measured by LC-MS/MS. Graphs showing (a) 4-HHE and (b) 4-HNE in salmon samples. Data are presented as the mean \pm S.D. $(n=6)$. Raw: control salmons without any cooking; boiled: salmons cooked by boiling; fried: salmons cooked by pan-frying; baked: salmons cooked by oven-baking. Similar letters denote no statistical differences between samples, otherwise it is statistically significant at $p<0.05$. 


\subsection{Elevated Oxidized PUFA Products Were Found in Cooked Salmons}

Oxidized PUFA products released by enzymatic and non-enzymatic oxidation of the salmon samples were measured by using LC-MS/MS. A total of 25 out of 42 were successfully detected. No cooking methods showed much effect on the level of enzymatic-oxidized PUFA products of the salmon. Only two types of analytes, RvE1 enzymatically derived from EPA, after pan-frying, and 14-hydroxy-DHA (HDHA) derived from DHA by both enzymatic and non-enzymatic oxidation, after oven-baking, were elevated significantly (Table 1).

The effect of cooking methods on the level of non-enzymatic-oxidized lipid products was more obvious (Figures 5 and 6 ). The cooking method that led to the strongest lipid peroxidation in salmon was pan-frying, where a significant increase in the amount of $15-\mathrm{F}_{2 \mathrm{t}}$-IsoP derived from AA, $15-\mathrm{F}_{3 \mathrm{t}}$-IsoP and $8-\mathrm{F}_{3 \mathrm{t}}$-IsoP derived from EPA, and 10-HDHA and 16-HDHA derived from DHA were detected. On the other hand, oven-baking also increased the levels of certain oxidized lipid products including $15-\mathrm{F}_{3 \mathrm{t}}$-IsoP derived from EPA and 4- $(R S)-4-\mathrm{F}_{4 \mathrm{t}}-\mathrm{NeuroPs}, 10-\mathrm{HDHA}$ and 16-HDHA derived from DHA. However, boiling the salmon only increased the concentration of $15-\mathrm{F}_{3 \mathrm{t}}-\mathrm{IsoP}$.

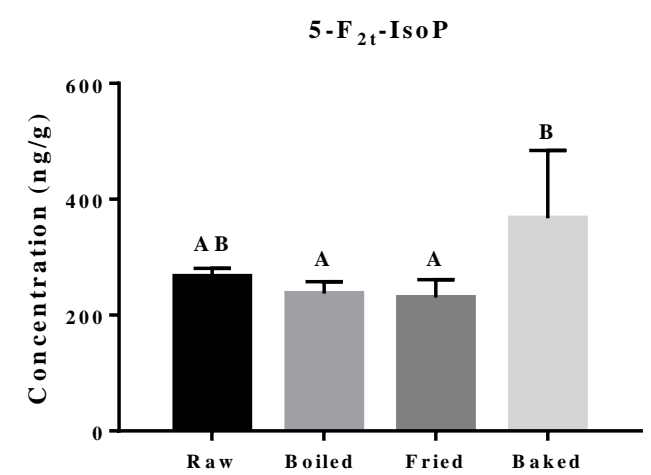

(a)

$17(R S)-17-F_{2 t}$-D ihom o-IsoP

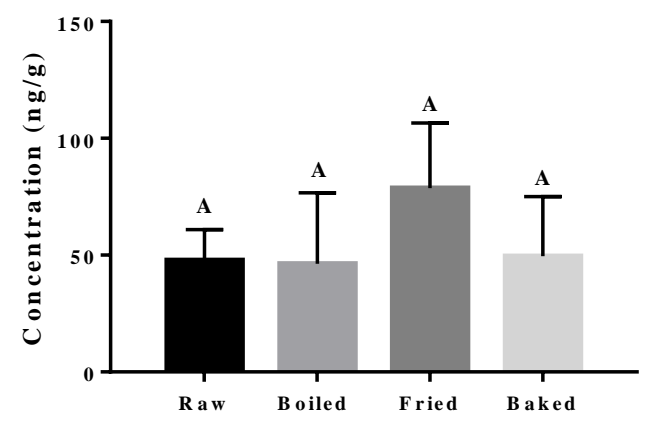

(c)

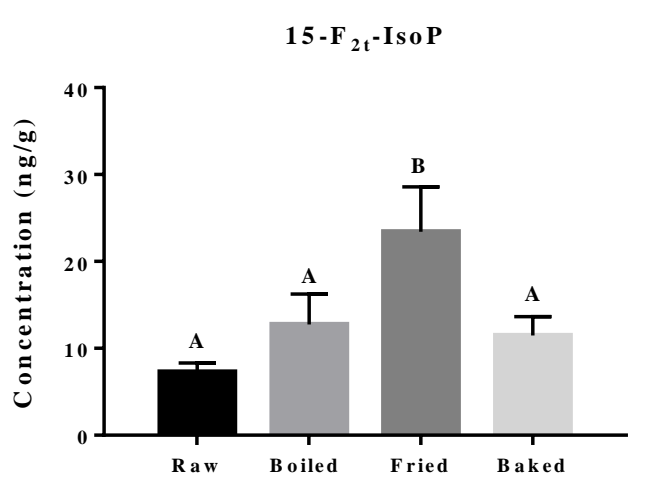

(b)

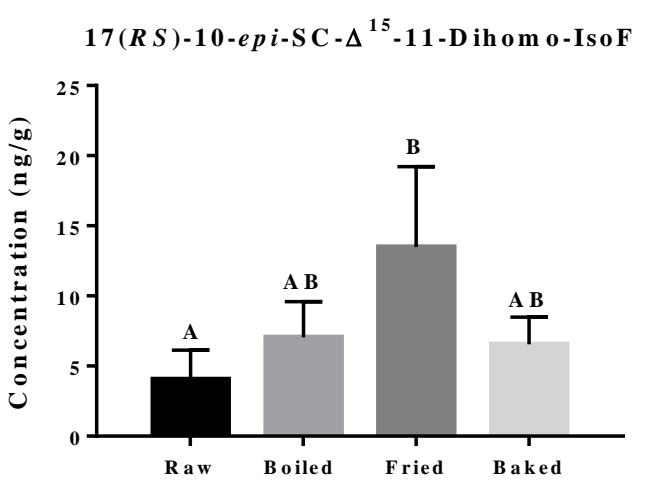

(d)

Figure 5. Concentration of non-enzymatically oxidized n-6 PUFA products measured in salmon samples. Graphs represent $(\mathbf{a}, \mathbf{b}) \mathrm{F}_{2}$-IsoPs derived from arachidonic acid and (c,d) dihomo-IsoP and dihomo-isofuran derived from adrenic acid. Data are presented as the mean \pm S.D. $(n=4)$. Raw: control salmons without any cooking; boiled: salmons cooked by boiling; fried: salmons cooked by pan-frying; baked: salmons cooked by oven-baking. Similar letters denote no statistical differences between samples, otherwise it is statistically significant at $p<0.05$. 


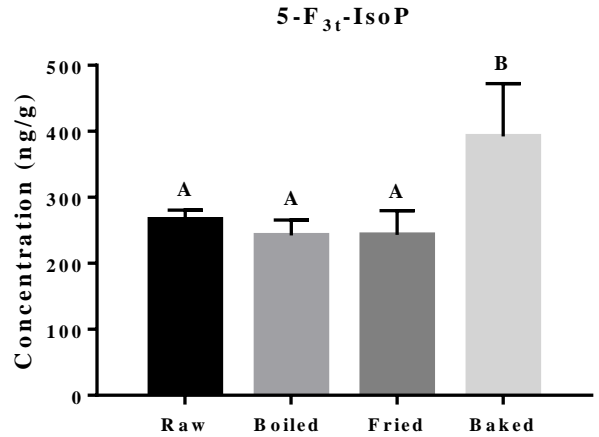

(a)

$15-F_{3 t}$-IsoP

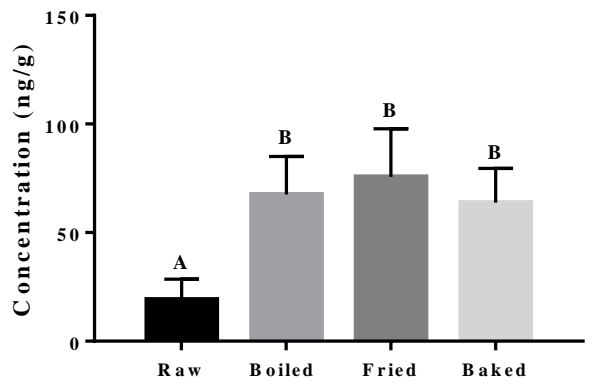

(c)

8-HDHA

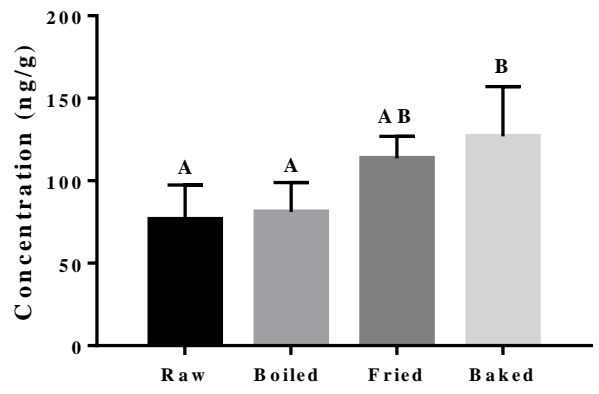

(e)

13-H D H A

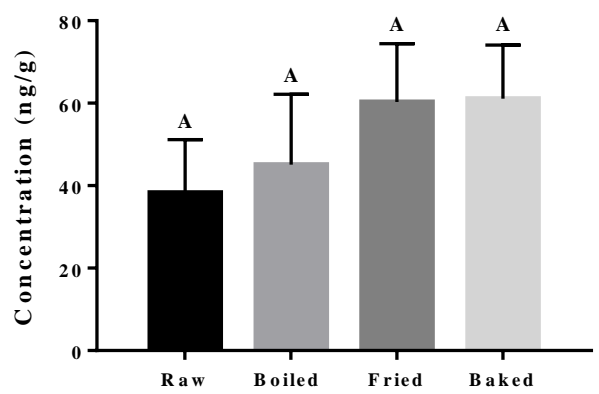

(g)

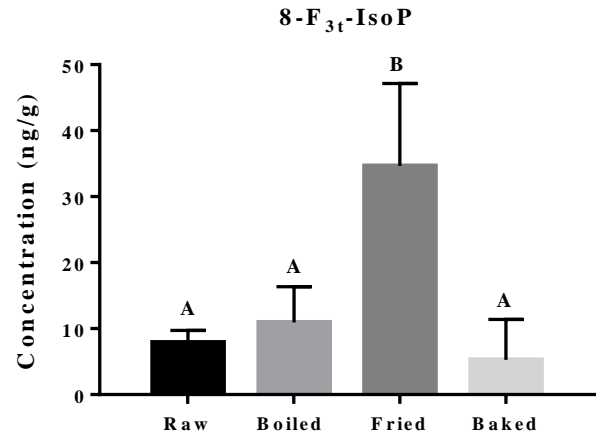

(b)

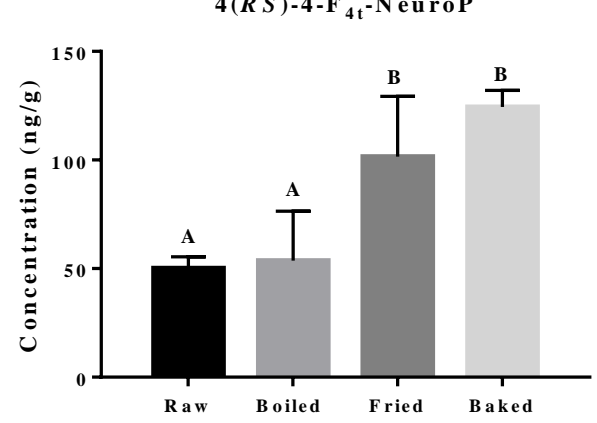

(d)

10 - H D H A

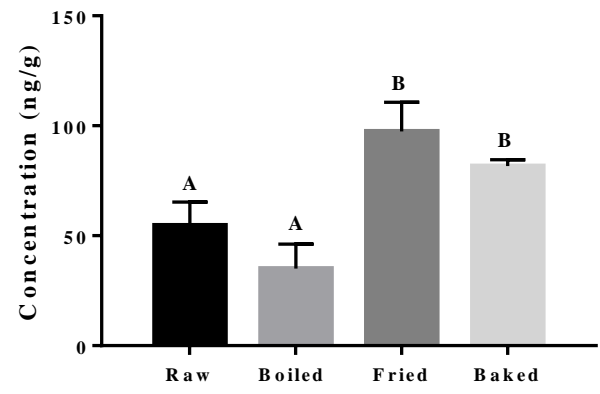

(f)

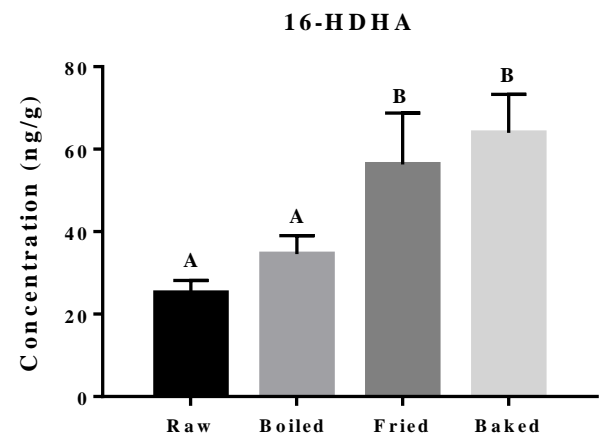

(h)

Figure 6. Concentration of non-enzymatically oxidized n-3 PUFA products measured in salmon samples. Graphs represent $(\mathbf{a}-\mathbf{c}) \mathrm{F}_{3}$-IsoPs derived from eicosapentaenoic acid and $(\mathbf{d}-\mathbf{h})$ NeuroPs and hydroxy-DHA (HDHA) derived from docosahexaenoic acid. Data are presented as the mean \pm S.D. $(n=4)$. Raw: control salmons without any cooking; boiled: salmons cooked by boiling; fried: salmons cooked by pan-frying; baked: salmons cooked by oven-baking. Similar letters denote no statistical differences between samples, otherwise it is statistically significant at $p<0.05$. 
Table 1. Concentration of enzymatically-oxidized products derived from n-3 and n-6 PUFAs measured in salmon samples.

\begin{tabular}{|c|c|c|c|c|}
\hline & Raw & Boiled & Fried & Baked \\
\hline \multicolumn{5}{|c|}{ Enzymatic oxidized lipid products derived from AA } \\
\hline 5(S)-HETE & $134.12 \pm 29.53^{a}$ & $150.46 \pm 33.12^{\mathrm{a}}$ & $265.91 \pm 92.79^{\mathrm{a}}$ & $201.24 \pm 7.79^{a}$ \\
\hline 8(S)-HETE & $19.98 \pm 8.02^{a}$ & $21.30 \pm 2.45^{\mathrm{a}}$ & $56.83 \pm 35.47^{a}$ & $29.80 \pm 4.81^{\mathrm{a}}$ \\
\hline 11(S)-HETE & $32.15 \pm 9.16^{\mathrm{a}}$ & $30.73 \pm 7.76^{\mathrm{a}}$ & $81.76 \pm 43.66^{\mathrm{a}}$ & $55.31 \pm 27.44^{\mathrm{a}}$ \\
\hline 12(S)-HETE & $138.95 \pm 50.97^{a}$ & $235.53 \pm 198^{a}$ & $142.66 \pm 86.35^{\mathrm{a}}$ & $98.54 \pm 42.05^{\mathrm{a}}$ \\
\hline 15(S)-HETE & $8.71 \pm 4.42^{\mathrm{a}}$ & $9.62 \pm 4.32^{\mathrm{a}}$ & $6.71 \pm 2.77^{a}$ & $7.90 \pm 2.69^{a}$ \\
\hline \multicolumn{5}{|c|}{ Enzymatic oxidized lipid products derived from EPA } \\
\hline RvE1 & $8.97 \pm 2.94^{\mathrm{a}}$ & $14.31 \pm 2.84^{\mathrm{a}}$ & $25.55 \pm 3.86^{b}$ & $11.80 \pm 3.41^{\mathrm{a}}$ \\
\hline \multicolumn{5}{|c|}{ Enzymatic oxidized lipid products derived from DHA } \\
\hline 4-HDHA & $63.36 \pm 17.08^{a}$ & $51.03 \pm 10.09^{a}$ & $78.24 \pm 15.16^{\mathrm{a}}$ & $88.54 \pm 17.42^{a}$ \\
\hline 7-HDHA & $36.45 \pm 6.32^{\mathrm{a}}$ & $35.28 \pm 7.88^{a}$ & $47.03 \pm 11.73^{\mathrm{a}}$ & $54.47 \pm 16.39^{a}$ \\
\hline 11-HDHA & $38.21 \pm 4.84^{\mathrm{a}}$ & $33.86 \pm 8.98^{a}$ & $55.02 \pm 7.74^{\mathrm{a}}$ & $48.91 \pm 13.09^{a}$ \\
\hline 14-HDHA & $40.43 \pm 3.42^{\mathrm{a}}$ & $35.62 \pm 10.38^{a}$ & $84.71 \pm 22.08^{b}$ & $89.26 \pm 13.17^{b}$ \\
\hline 17-HDHA & $391.58 \pm 43.80^{\mathrm{a}}$ & $539.14 \pm 149.46^{\mathrm{a}}$ & $489.99 \pm 36.43^{\mathrm{a}}$ & $790.34 \pm 273.12^{a}$ \\
\hline RvD1 & $19.46 \pm 8.50^{\mathrm{a}}$ & $19.11 \pm 2.90^{\mathrm{a}}$ & $23.82 \pm 3.81^{\mathrm{a}}$ & $37.43 \pm 12.13^{\mathrm{a}}$ \\
\hline NPD1 & $11.41 \pm 3.01^{\mathrm{a}}$ & $15.44 \pm 2.70^{\mathrm{a}}$ & $24.68 \pm 6.20^{s}$ & $11.93 \pm 2.33^{a}$ \\
\hline
\end{tabular}

Data are presented as the mean \pm S.D. $(n=4), n g / g$ of tissue. Raw: control salmons without any cooking; boiled: salmons cooked by boiling; fried: salmons cooked by pan-frying; baked: salmons cooked by oven-baking. HETE: hydroxyeicosatetraenoic acid; HDHA: hydroxy-DHA; RvD1: resolving D1; NPD1: neuroprotection D1. Similar letters in superscript denote no statistical differences between samples, otherwise it is statistically significant at $p<0.05$.

\section{Discussion}

Regular consumption of long chain n-3 PUFAs, namely EPA and DHA, has been proposed to have health benefits such as improving blood flow and blood pressure, cardiovascular disease prevention and neurodegenerative disease protection [2,4,30]. In general, fatty fish is a rich source of EPA and DHA. American Heart Association recommended to the public to consume regular fatty fish at least twice a week to obtain the health benefits of EPA and DHA [31]. However, fish in most countries is consumed cooked and not raw; therefore, concerns about the method of cooking may lead to the reduction of n-3 PUFAs and the generation of potentially toxic oxidized lipid products due to the high heat.

In this study, the content of PUFAs, oxidized PUFA products and level of lipid peroxidation in raw, boiled, pan-fried and oven-baked salmon were examined. None of the cooking methods was able to significantly reduce either $n-3$ or n-6 PUFAs in the salmon samples, which indicates that the quality of n-3 PUFAs in benefitting health was not altered after cooking. This matched the findings in the study of Bastias et al., where the fatty acid profile in salmon remained unchanged after cooking by four different methods [32]. In a similar study, cooking methods including boiling, frying and roasting of humpback salmon showed that only frying significantly reduced EPA and DHA [13]. The group suggested that the decreased PUFAs in the salmon may be caused by the longer frying time. The frying time used was 15-20 min, but in this study, it took $10 \mathrm{~min}$; in comparison, the longer frying time may have raised the oxidation of PUFAs in the salmon and subsequent loss of PUFAs. Although in this study, cooking oil was not used in the frying process, the reduction of PUFAs in pan-fried salmon may occur if cooking oil is added during frying. Flaskerud et al. found that pan-frying trout in corn oil and canola oil had no effect on the level of PUFAs in the fish, but pan-frying with peanut oil and high oleic sunflower oil induced the reduction of EPA and of EPA and DHA, respectively [33]. This matched the findings from Gladyshev et al., who used sunflower oil to fry the salmon [13]. The decline of EPA and DHA is the result of the fat of fish filets transferring to the cooking oil when pan-frying in sunflower oil. Sioen et al. proposed that the fat of the fish is leached out during the frying process 
to the cooking oil, and the free radicals generated in the hot cooking oil in return oxidize the fat of the fish [34]. Thereafter, another similar study was conducted by Gladyshev et al. with four different fish species including sea trout, herring, rock sole and cod [35]. They concluded that the difference of EPA and DHA content in fish depends on the fish type and the use of cooking oil, and not the cooking methods. In their report, only the fried Norwegian trout showed a significant reduction of EPA and DHA compared to raw trout. Again, the loss of EPA and DHA in fried Norwegian trout was mainly due to the sunflower oil during frying.

Heating PUFA will generate numerous types of oxidized products that may be advantageous and disadvantageous to human health. Unexpectedly, PUFA levels were not significantly reduced by the cooking methods, but the results of the PV test, TBARS test, quantification of 4-HHE and 4-HNE and the oxidized products showed alteration. The large standard deviation of the mean PUFAs particularly after frying or baking signified that cooking methods perhaps had an impact on the PUFA concentration. Of the salmon samples, frying and baking induced lipid peroxidation in the salmon where frying had the strongest effect among the three cooking methods. The difference observed in the level of lipid peroxidation in salmon cooked by the different methods is attributed to the heat temperature. Boiling is a mild cooking method, and the temperature generated through boiling was the lowest compared to other cooking methods where the maximum is $100{ }^{\circ} \mathrm{C}$, i.e., the boiling point of water. Moreover, the cooking time was not long compared to baking since the heat transfer by boiling is very effective as the salmon is immersed into the hot water, allowing energy transfer to the food by constant collision of the food molecules through water convection [36]. The short cooking time and low temperature may explain the low level of peroxides and reactive aldehydes in boiled fish compared to raw fish.

On the other hand, pan-frying transfers heat through conduction at a temperature between $190{ }^{\circ} \mathrm{C}$ and $210^{\circ} \mathrm{C}$. Even though the temperature used in pan-frying is twice that of boiling, the cooking time is similar to boiling, as the temperature can only transfer to the surface of the food through conduction, which then rapidly dehydrates the food surface and causes Maillard browning and flavor development [35]. The interior of the food can remain moist, and the temperature usually does not exceed $100{ }^{\circ} \mathrm{C}$, as it is insulated by the outer surface and the fat of the food. However, the temperature of the salmon surface is highly exposed to free radicals of the oil released by thermal oxidation in the presence of oxygen, i.e., air and water. As a consequence, the lipid peroxidation caused by frying is strong compared to other methods, and as a result, the levels of peroxides and reactive aldehydes are high.

As for baking, the temperature used was $200{ }^{\circ} \mathrm{C}$ and the cooking time was the longest (15 min) since the heat transfer in baking is air convection and radiation, which is not as efficient as boiling and frying. The air in the oven is a thousand-times less dense than water, so the energy transfer by collisions of hot air molecules and food are low [36]. Therefore, it takes more time to heat up the food in the oven, and the inner temperature of the food is much lower than the surrounding temperature. Subsequently, the rate of lipid peroxidation by baking is less strong compared to pan-frying, although the temperature used is similar and the cooking time longer.

The elevation of lipid peroxidation in salmon fillet after frying was further supported by the oxidized PUFA products measured. One product, $15-\mathrm{F}_{2 \mathrm{t}}$-IsoP derived from AA, is formed via ROS/free radicals non-enzymatically and is a renowned in vivo oxidative stress biomarker in vivo. It was also significantly induced in the fried salmon sample compared to boiling or baking. This observation indicates frying does increase the free radical production through thermal oxidation of the salmon fillet. Similar products from n-3 PUFA, namely $15-\mathrm{F}_{3 \mathrm{t}}$-IsoP and $8-\mathrm{F}_{3 \mathrm{t}}-\mathrm{IsoP}$ from EPA and 4(RS)-4- $\mathrm{F}_{4 \mathrm{t}}-\mathrm{NeuroP}$ from DHA, are also formed through ROS/free radicals in non-enzymatic oxidation. Elevation of $15-\mathrm{F}_{3 \mathrm{t}}$-IsoP was also found in boiled and baked salmon and no change in $8-\mathrm{F}_{3 \mathrm{t}}$-IsoP, which matched the PV and TBARS findings that the level of lipid peroxidation produced from boiling and baking is less strong compared to frying. It was surprising to discover that the baking and frying methods increased several DHA-derived oxidized products, but most notably $4(R S)-4-\mathrm{F}_{4 \mathrm{t}}-\mathrm{NeuroP}$. Recent studies found 
that $4(R S)-4-\mathrm{F}_{4 \mathrm{t}}-\mathrm{NeuroP}$ is cardio-protective, containing an anti-arrhythmic factor that can repair the RyR2 ryanodine receptor in the heart and maintain calcium homeostasis $[17,18,37]$. Furthermore, $4(R S)-4-\mathrm{F}_{4 \mathrm{t}}-\mathrm{NeuroP}$ improved heart variability, reduced pro-inflammatory cytokines and reduced thrombosis with improved blood flow [17].

In this study, pan-frying the salmon generated high levels of DHA-derived oxidized products. This is probably due to the strong heat contact in pan frying and potentially promoted secondary lipid peroxidation to generate aldehydes such as 4-HHE and 4-HNE that can cross-link with the protein [38] in the salmon. The elevation of 4-HHE in pan-fried salmon may not be disadvantageous to human health. Although 4-HHE is known to be neurotoxic, to increase during digestion of fatty fish and even to induce gut inflammation $[39,40]$, a low concentration of 4-HHE was found to be cardioprotective by activating Nrf2 [21,22]. Furthermore, the results of the TBARS assay also showed pan-frying to be the only cooking method strong enough to increase the level of MDA in salmon. Both results support that the high temperature contact and heat conduction of the frying led to further degradation of the oxidized products of DHA.

\section{Conclusions}

The results of this study provided a new insight into how cooking methods affect the composition of PUFAs and oxidized PUFA products in salmon. Prior to the study, we hypothesized that it was possible to reduce the amount of PUFAs and increase their oxidized products in salmon through common cooking methods since the high temperature used could oxidize PUFAs due to the numerous double bonds in the structure. However, the results were unexpected. While the quantified inherent margin of error of the PUFAs showed no reduction after cooking, oxidized products of PUFAs were clearly increased, suggesting that indeed a proportion of the n-3 PUFA, namely EPA and DHA, was modified and generated bioactive compounds such as $4(R S)-4-\mathrm{F}_{4 \mathrm{t}}-\mathrm{NeuroP}$.

Author Contributions: K.S.L. and J.C.-Y.L. designed the study. Analytical measurements were performed by K.S.L. and J.-M.G. T.D. synthesized the IBMM compounds. Data interpretation was made by K.S.L. and J.C.-Y.L. K.S.L., J.-M.G., T.D. and J.C.-Y.L. contributed in the writing of the manuscript.

Funding: This research was funded by The University of Hong Kong, Small Project Funding (No. 201409176019).

Conflicts of Interest: The authors declare no conflict of interest.

\section{References}

1. Rajaram, S. Health benefits of plant-derived $\alpha$-linolenic acid. Am. J. Clin. Nutr. 2014, 100 (Suppl. 1), 443S-448S. [CrossRef] [PubMed]

2. Tapiero, H.; Ba, G.N.; Couvreur, P.; Tew, K.D. Polyunsaturated fatty acids (PUFA) and eicosanoids in human health and pathologies. Biomed. Pharmacother. 2002, 56, 215-222. [CrossRef]

3. Calder, P.C. N-3 polyunsaturated fatty acids, inflammation, and inflammatory diseases. Am. J. Clin. Nutr. 2006, 83, 1505S-1519S. [CrossRef] [PubMed]

4. Zhang, W.; Li, P.; Hu, X.; Zhang, F.; Chen, J.; Gao, Y. Omega-3 polyunsaturated fatty acids in the brain: Metabolism and neuroprotection. Front. Biosci. 2011, 16, 2653-2670. [CrossRef]

5. Thomas, J.; Thomas, C.J.; Radcliffe, J.; Itsiopoulos, C. Omega-3 fatty acids in early prevention of inflammatory neurodegenerative disease: A focus on Alzheimer's disease. Biomed. Res. Int. 2015, 2015, 172801. [CrossRef] [PubMed]

6. Eser, P.O.; Vanden Heuvel, J.P.; Araujo, J.; Thompson, J.T. Marine- and plant-derived omega-3 fatty acids differentially regulate prostate cancer cell proliferation. Mol. Clin. Oncol. 2013, 1, 444-452. [CrossRef] [PubMed]

7. Burdge, G.C.; Calder, P.C. Conversion of $\alpha$-linolenic acid to longer-chain polyunsaturated fatty acids in human adults. Reprod. Nutr. Dev. 2005, 45, 581-597. [CrossRef] [PubMed]

8. Ohshima, T.; Shozen, K.; Ushio, H.; Koizumi, C. Effects of grilling on formation of cholesterol oxides in seafood products rich in polyunsaturated fatty acids. Food Sci. Technol. 1996, 29, 94-99. [CrossRef] 
9. Sampaio, G.R.; Bastos, D.H.M.; Soares, R.A.M.; Queiroz, Y.S.; Torres, E.A.F.S. Fatty acids and cholesterol oxidation in salted and dried shrimp. Food Chem. 2006, 95, 344-351. [CrossRef]

10. Sant'Ana, L.S.; Mancini, J. Influence of the addition of antioxidants in vivo on the fatty acid composition of fish fillets. Food Chem. 2000, 68, 175-178. [CrossRef]

11. Tarley, C.R.T.; Visentainer, J.V.; Matsushita, M.; de Souza, N.E. Proximate composition, cholesterol and fatty acids profile of canned sardines (Sardinella brasiliensis) in soybean oil and tomato sauce. Food Chem. 2004, 88, 1-6. [CrossRef]

12. Echarte, M.; Zulet, M.A.; Astiasaran, I. Oxidation process affecting fatty acids and cholesterol in fried and roasted salmon. J. Agric. Food Chem. 2001, 49, 5662-5667. [CrossRef] [PubMed]

13. Gladyshev, M.I.; Sushchik, N.N.; Gubanenko, G.A.; Demirchieva, S.M.; Kalachova, G.S. Effect of way of cooking on content of essential polyunsaturated fatty acids in muscle tissue of humpback salmon (Oncorhynchus gorbuscha). Food Chem. 2006, 96, 446-451. [CrossRef]

14. Stolyhwo, A.; Kolodziejska, I.; Sikorski, Z.E. Long chain polyunsaturated fatty acids in smoked atlantic mackerel and baltic sprats. Food Chem. 2006, 94, 589-595. [CrossRef]

15. Milne, G.L.; Dai, Q.; Roberts, L.J., 2nd. The isoprostanes-25 years later. Biochim. Biophys. Acta 2015, 1851, 433-445. [PubMed]

16. Alkazemi, D.; Jackson, R.L., 2nd; Chan, H.M.; Kubow, S. Increased F3-isoprostanes in the canadian inuit population could be cardioprotective by limiting F2-isoprostane production. J. Clin. Endocrinol. Metab. 2016, 101, 3264-3271. [CrossRef] [PubMed]

17. Roy, J.; Oger, C.; Thireau, J.; Roussel, J.; Mercier-Touzet, O.; Faure, D.; Pinot, E.; Farah, C.; Taber, D.F.; Cristol, J.P.; et al. Nonenzymatic lipid mediators, neuroprostanes, exert the antiarrhythmic properties of docosahexaenoic acid. Free Radic. Biol. Med. 2015, 86, 269-278. [CrossRef] [PubMed]

18. Roy, J.; Fauconnier, J.; Oger, C.; Farah, C.; Angebault-Prouteau, C.; Thireau, J.; Bideaux, P.; Scheuermann, V.; Bultel-Ponce, V.; Demion, M.; et al. Non-enzymatic oxidized metabolite of DHA, 4(RS)-4-F4T-neuroprostane protects the heart against reperfusion injury. Free Radic. Biol. Med. 2017, 102, 229-239. [CrossRef] [PubMed]

19. Gladine, C.; Newman, J.W.; Durand, T.; Pedersen, T.L.; Galano, J.M.; Demougeot, C.; Berdeaux, O.; Pujos-Guillot, E.; Mazur, A.; Comte, B. Lipid profiling following intake of the omega 3 fatty acid DHA identifies the peroxidized metabolites $\mathrm{F} 4$-neuroprostanes as the best predictors of atherosclerosis prevention. PLoS ONE 2014, 9, e89393. [CrossRef] [PubMed]

20. Long, E.K.; Murphy, T.C.; Leiphon, L.J.; Watt, J.; Morrow, J.D.; Milne, G.L.; Howard, J.R.H.; Picklo, M.J. Trans-4-hydroxy-2-hexenal is a neurotoxic product of docosahexaenoic (22:6;n-3) acid oxidation. J. Neurochem. 2008, 105, 714-724. [CrossRef] [PubMed]

21. Ishikado, A.; Morino, K.; Nishio, Y.; Nakagawa, F.; Mukose, A.; Sono, Y.; Yoshioka, N.; Kondo, K.; Sekine, O.; Yoshizaki, T.; et al. 4-hydroxy hexenal derived from docosahexaenoic acid protects endothelial cells via NRF2 activation. PLoS ONE 2013, 8, e69415. [CrossRef] [PubMed]

22. Ishikado, A.; Nishio, Y.; Morino, K.; Ugi, S.; Kondo, H.; Makino, T.; Kashiwagi, A.; Maegawa, H. Low concentration of 4-hydroxy hexenal increases heme oxygenase-1 expression through activation of NRF2 and antioxidative activity in vascular endothelial cells. Biochem. Biophys. Res. Commun. 2010, 402, 99-104. [CrossRef] [PubMed]

23. Toru, T.; Yuichiro, M.; Mayumi, M. Determination of peroxide value by the colorimetric iodine method with protection of iodide as cadmium complex. Lipids 1978, 13, 147-151.

24. Papastergiadis, A.; Mubiru, E.; Van Langenhove, H.; De Meulenaer, B. Malondialdehyde measurement in oxidized foods: Evaluation of the spectrophotometric thiobarbituric acid reactive substances (TBARS) test in various foods. J. Agric. Food Chem. 2012, 60, 9589-9594. [CrossRef] [PubMed]

25. Dupuy, A.; Le Faouder, P.; Vigor, C.; Oger, C.; Galano, J.M.; Dray, C.; Lee, J.C.; Valet, P.; Gladine, C.; Durand, T.; et al. Simultaneous quantitative profiling of 20 isoprostanoids from omega-3 and omega-6 polyunsaturated fatty acids by LC-MS/MS in various biological samples. Anal. Chim. Acta 2016, 921, 46-58. [CrossRef] [PubMed]

26. Lee, C.Y.; Jenner, A.M.; Halliwell, B. Rapid preparation of human urine and plasma samples for analysis of F2-isoprostanes by gas chromatography-mass spectrometry. Biochem. Biophys. Res. Commun. 2004, 320, 696-702. [CrossRef] [PubMed] 
27. Lee, Y.Y.; Wong, C.K.; Oger, C.; Durand, T.; Galano, J.M.; Lee, J.C. Prenatal exposure to the contaminant perfluorooctane sulfonate elevates lipid peroxidation during mouse fetal development but not in the pregnant dam. Free Radic. Res. 2015, 49, 1015-1025. [CrossRef] [PubMed]

28. Lee, Y.Y.; Crauste, C.; Wang, H.; Leung, H.H.; Vercauteren, J.; Galano, J.M.; Oger, C.; Durand, T.; Wan, J.M.; Lee, J.C. Extra virgin olive oil reduced polyunsaturated fatty acid and cholesterol oxidation in rodent liver: Is this accounted for hydroxytyrosol-fatty acid conjugation? Chem. Res. Toxicol. 2016, 29, 1689-1698. [CrossRef] [PubMed]

29. Douny, C.; Bayram, P.; Brose, F.; Degand, G.; Scippo, M.L. Development of an LC-MS/MS analytical method for the simultaneous measurement of aldehydes from polyunsaturated fatty acids degradation in animal feed. Drug Test. Anal. 2016, 8, 458-464. [CrossRef] [PubMed]

30. Gluck, T.; Alter, P. Marine omega-3 highly unsaturated fatty acids: From mechanisms to clinical implications in heart failure and arrhythmias. Vasc. Pharmacol. 2016, 82, 11-19. [CrossRef] [PubMed]

31. Kris-Etherton, P.M.; Harris, W.S.; Appel, L.J.; American Heart Association. Nutrition, C. Fish consumption, fish oil, omega-3 fatty acids, and cardiovascular disease. Circulation 2002, 106, 2747-2757. [CrossRef] [PubMed]

32. Bastias, J.M.; Balladares, P.; Acuna, S.; Quevedo, R.; Munoz, O. Determining the effect of different cooking methods on the nutritional composition of salmon (Salmo salar) and chilean jack mackerel (Trachurus murphyi) fillets. PLoS ONE 2017, 12, e0180993. [CrossRef] [PubMed]

33. Flaskerud, K.; Bukowski, M.; Golovko, M.; Johnson, L.; Brose, S.; Ali, A.; Cleveland, B.; Picklo, M.; Raatz, S. Effects of cooking techniques on fatty acid and oxylipin content of farmed rainbow trout (Oncorhynchus mykiss). Food Sci. Nutr. 2017, 5, 1195-1204. [CrossRef] [PubMed]

34. Sioen, I.; Haak, L.; Raes, K.; Hermans, C.; De Henauw, S.; De Smet, S.; Van Camp, J. Effects of pan-frying in margarine and olive oil on the fatty acid composition of cod and salmon. Food Chem. 2006, 98, 609-617. [CrossRef]

35. Gladyshev, M.I.; Sushchik, N.N.; Gubanenko, G.A.; Demirchieva, S.M.; Kalachova, G.S. Effect of boiling and frying on the content of essential polyunsaturated fatty acids in muscle tissue of four fish species. Food Chem. 2007, 101, 1694-1700. [CrossRef]

36. McGee, H. On Food and Cooking: The Science and Lore of the Kitchen; Scribner: New York, NY, USA, 2004.

37. Roy, J.; Le Guennec, J.Y.; Galano, J.M.; Thireau, J.; Bultel-Ponce, V.; Demion, M.; Oger, C.; Lee, J.C.; Durand, T. Non-enzymatic cyclic oxygenated metabolites of omega-3 polyunsaturated fatty acid: Bioactive drugs? Biochimie 2016, 120, 56-61. [CrossRef] [PubMed]

38. Long, E.K.; Picklo, M.J. Trans-4-hydroxy-2-hexenal, a product of n-3 fatty acid peroxidation: Make some room HNE. Free Radic. Biol. Med. 2010, 49, 1-8. [CrossRef] [PubMed]

39. Larsson, K.; Harrysson, H.; Havenaar, R.; Alminger, M.; Undeland, I. Formation of malondialdehyde (MDA), 4-hydroxy-2-hexenal (HHE) and 4-hydroxy-2-nonenal (HNE) in fish and fish oil during dynamic gastrointestinal in vitro digestion. Food Funct. 2016, 7, 1176-1187. [CrossRef] [PubMed]

40. Awada, M.; Soulage, C.O.; Meynier, A.; Debard, C.; Plaisancié, P.; Bérengère, B.; Picard, G.; Loizon, E.; Chauvin, M.A.; Estienne, M.; et al. Dietary oxidized n-3 PUFA induce oxidative stress and inflammation: Role of intestinal absorption of 4-HHE and reactivity in intestinal cells. J. Lipid Res. 2012, 53, 3069-3080. [CrossRef] [PubMed]

(C) 2018 by the authors. Licensee MDPI, Basel, Switzerland. This article is an open access article distributed under the terms and conditions of the Creative Commons Attribution (CC BY) license (http://creativecommons.org/licenses/by/4.0/). 